\title{
Uncovering the decision-making work of transferring dying patients home from critical care units: An integrative review
}

\section{Authors:}

Yanxia LIN ${ }^{1}$, Michelle MYALL ${ }^{2}$, Nikki JARRETT ${ }^{3}$

1. PhD Candidate, Faculty of Health Sciences, University of Southampton, RN, BSc, MSc;

2. PhD, Senior research fellow, Faculty of Health Sciences, University of Southampton, BSc. (Hons); MA; PhD;

3. PhD, Lecturer in Health Sciences, Deputy Programme Lead MPhil/PhD, Faculty of Health Sciences, RN, BSc (Hons), PGCertAP, PhD.

\section{Corresponding Author}

Yanxia LIN

Faculty of Health Sciences

University of Southampton

Room 1019 Building 45

Highfield Campus

Southampton

SO17 1BJ

Phone: 07421899983

Telephone: 02380593228

Email: yl8g14@soton.ac.uk

Twitter: Yeelin00

\section{Acknowledgements}

Professor Carl May is thanked for his helpful comments on an earlier draft of this manuscript. The authors also wish to thank the China Scholarship Council (CSC) for funding the PhD study from which this paper derives.

\section{Conflict of interest}

No conflict of interest has been declared by the authors.

\section{Funding statement}

This report is funded by the China Scholarship Council (CSC). 
$\longrightarrow$ 


\title{
Uncovering the decision-making work of transferring dying patients home from critical care units: An integrative review
}

\begin{abstract}
Aims. To understand how decisions are made to transfer dying patients home from critical care units.

Background. Many people prefer a home death, but a high proportion die in critical care units. Transferring dying patients home is recognized to be complex but transfer decisionmaking itself remains unclear.
\end{abstract}

Design. Integrative review.

Data sources. Seven bibliographic databases (origin to 2015), grey literature and reference lists were searched.

Review Methods. An integrative review method was used to synthesize data from diverse sources. Papers were selected through title and abstract screening, and full-text reviewing, using inclusion and exclusion criteria derived from review questions. Following quality appraisal, data were extracted, and synthesized using Normalisation Process Theory as a framework.

Results. The number of patients transferred home ranged from one to 346 , with most papers reporting on the transfer of one or two patients. Four themes regarding transfer decision-making work were generated: divergent views and practice, multiple stakeholders' involvement in decision-making, collective work, and limited understanding of individuals' experiences.

Conclusion. The practice of transferring patients home to die and its decision-making varies internationally and is usually influenced by the care system, culture or religion. It is less common to transfer patients home to die from critical care units in western societies. A better understanding of the decision-making work was obtained but mainly from the perspective of hospital-based healthcare professionals. Further research is needed to develop decision-making practice guidance to facilitate patients' wishes to die at home.

Keywords: critical care, decision-making, home nursing, literature review, Normalisation Process Theory, nursing, patient discharge, place of death, transfer home 


\section{SUMMARY STATEMENT}

\section{Why is this review needed?}

- Many people prefer to die at home, but this is seldom achieved, particularly in western societies where the majority of people die in hospital.

- $\quad$ Although the practice of transferring home dying patients from critical care is understood to be complex and challenging from the perspective of health care professionals, the decision-making involved remain less clear.

- A more informed understanding of the transfer decision-making process may enable patients' preferences of place of death to be met.

\section{What are the key findings?}

- In an international context, the decision-making behind transferring home dying patients from critical care units was identified to be a complex process, involving different societal traditions, cultures, religions, and health care systems.

- Transferring patients home to die has not been routinely incorporated in critical care. Barriers include: lack of criteria for patients that can be transferred home; unclear mechanisms for multiple stakeholders' involvement; challenges of cooperation among various healthcare teams and families; and omission of evaluation by individuals involved.

- This review showed that Normalisation Process Theory offers an appropriate theoretical framework to facilitate the analysis of heterogeneous data from papers concerning complex clinical practice.

\section{How should the findings be used to influence policy, practice, research and education?}

- The transfer of dying patients home from critical care could become routine practice (when it is their preference and clinically appropriate), if guidelines are developed that can be adapted locally to take into account cultural, individual health and contextual differences.

- Guidelines for transfer decision-making need to be developed that incorporates criteria for patients to be transferred home, recognises all involved decision-makers, the process of their engagement in decision-making, the practical work and decisions needed for successful transfer to take place, and post-transfer evaluation by decisionmakers. 
- Further research is needed to investigate the practice of transferring home in contexts outside of western societies where this is achieved more routinely, and to understand a wider range of perspectives especially those of nurses, patients and their families. 


\section{Introduction}

Place of death has been an increasingly important topic within the field of end-of-life care and decision-making. Evidence suggested that $31 \%-87 \%$ of patients, $25 \%-64 \%$ of caregivers, and $49 \%-70 \%$ of the public preferred to die at home (Gomes et al. 2013b). However, in many western countries only $16 \%-57 \%$ eventually achieved a home death, and most died in hospital or other institutions (Cohen et al. 2015). A review of over 16 million deaths in 45 populations reported that $54 \%$ (46-60\%) of all deaths occurred in hospital and $12 \%(0-20 \%)$ in residential care facilities with more institution deaths in western countries compared to those in Albania, China, Chile, Lithuania, and Serbia (Broad et al. 2013).

A recent survey in the UK suggested that a home death can be more peaceful for the patient and less intense for the families' grieving processes than a hospital death if the following provisos are in place: patient's preferences are discussed, their general practitioner (GP) can visit them at home, and they have the support of their family (Gomes et al. 2015). However, results from an audit show that of 422 patients who died in seven critical care settings in two UK hospitals, 100 (23.7\%) who could have been transferred home to die were not (Coombs et al. 2015a).

\section{Background}

Many patients in critical care units (CCUs) which include intensive care units (ICUs), intensive therapy units (ITUs), and high dependency units (HDUs) (NICE 2009; NHS Choices 2015) prefer to die at home. A survey of 46 ICUs in the Netherlands found that $46 \%$ of units had discharged dying patients home at the request of patients or their families (Hoogveld et al. 2015). However, a substantial number of patients still die in ICUs. In the USA, approximately $20 \%$ of deaths occurred in ICUs after admission (Angus et al. 2004), and in the UK, $30 \%$ of patients died in ICUs following admission (Wunsch et al. 2005).

Transferring dying patients home can present many challenges. For example, patients in critical care often suffer cardiopulmonary failure (Blot et al. 2015), tend to be unstable, and receive ventilation and hemodynamic support (Bauchmuller and Faulds 2015). A survey of 243,553 patients from 271 ICUs in 188 hospitals in the USA reported that $27 \%$ received mechanical ventilation and $24.3 \%$ were treated with vasoactive medication (Lilly et al. 2011). These challenges can impact on decision-making to transfer dying patients home.

Complex medical practice has been investigated from a social science perspective (May and Finch 2009; May et al. 2009; Murray et al. 2010). According to May (2013), complexity can be defined as the work required, and the factors that promote or inhibit implementing and embedding a practice, which requires collective action and has contingent outcomes. The 
practice can be complex for all individuals involved in the process. Therefore, to understand the complexity of transfer home and its decision-making, the work required and the factors that promote or inhibit implementing the transfer should be identified, understood and explained.

Although there is substantial literature on both place of death and decision making, an indepth understanding of the decision-making of transferring the dying patient home is lacking. A more informed understanding of this process may enable patients' preferences of place of death to be met.

\section{The review}

\section{Aims}

This review aimed to understand how decisions were made to transfer dying patients home from CCUs. The review questions were:

1. How were decisions made to transfer dying patients home?

2. What work was needed to make decisions on transferring dying patients home?

3. Who were involved in the decision-making processes?

4. What were the barriers and facilitators to the decision-making of transferring patients home to die from the perspectives of all involved?

\section{Design}

As this review included research and non-research sources, the integrative review method was applied (Whittemore and Knafl 2005). This approach is used for generalizing inferences, summarizing and synthesizing accumulated evidence and interrelating findings from existing sources to generate new, integrated knowledge (Soares et al. 2014). It allows for combining diverse primary sources and multiple perspectives on a problem or phenomenon to inform evidence-based practice initiatives (Whittemore and Knafl 2005). Researchers have successfully adapted this method to integrate research and non-research documents in evidence reviews (Ten Ham et al. 2016). An in-depth understanding of complex problems can be gained by using this literature review method.

Based on the guiding framework, this review was conducted in a systematic way that applied detailed, rigorous and explicit strategies to identifying review questions, searches, developing inclusion and exclusion criteria, appraising and synthesising data, and presenting findings (Whittemore and Knafl 2005). 


\section{Search method}

The search strategy was informed by the guidance described by Conn et al. (2003a); Conn et al. (2003b). To identify the maximum number of eligible studies or sources, a three-phase search method was used. Firstly, searches were conducted in the following bibliographic databases: Medline, CINAHL, Embase, AMED, PsycINFO, Web of Science and Scopus. Secondly, websites for the National Institute for Health and Care Excellence (NICE), the British Library and Open Grey were searched for grey literature. Thirdly, a manual search of references from all relevant articles was carried out to identify additional papers.

The systematic search in Medline using a combination of keywords and MeSH terms (see supplementary information 1) formed the basis of search strategies in other databases or websites. Searches were completed in 3-28 May 2015 and papers published to the present date were identified.

\section{Inclusion and exclusion criteria}

The inclusion and exclusion criteria for the literature are presented using PICOS/PEOS framework (patient, intervention/exposure, outcomes, and study/source type). See Table 1. In order to integrate diverse evidence, non-research documents such as clinical reports were included. Only papers written in English or Chinese were included. Papers were selected through title and abstract screening, and full-text reviewing, based on inclusion and exclusion criteria.

\section{Search outcome}

The result of paper selection is outlined in Figure 1. After the removal of duplicates, in total, 17,644 results were obtained. The majority of these $(n=17,624)$ were excluded at the title and abstract screening stage. An additional seven papers were retrieved from reference lists of the remaining 20 papers resulting in 27 papers eligible for full text screening. Of these, 20 papers, all of which were written in English, met the inclusion criteria.

The design varied among the twenty papers. Research papers included qualitative studies $(n=3)$, quantitative observational studies $(n=2)$ and mixed methods studies $(n=1)$. Nonresearch documents included clinical case reports and opinion pieces $(n=12)$ and service description $(n=2)$.

\section{Quality appraisal}

A gold standard for appraising quality in reviews is lacking and evaluating the quality of papers in an integrative review is complex (Whittemore and Knafl 2005). The diverse designs of included documents prevented the use of a single appraisal tool. In an integrative 
review involving theoretical and empirical sources, Whittemore and Knafl (2005) suggested two quality evaluation tools to be used for each type of source. For this review, two checklists were applied to evaluate the quality of research studies and non-research documents (see supplementary information 2). Checklists were used to aid critical consideration of the evidence but scores are not provided since all domains are not treated equally making the scores meaningless.

The Mixed Methods Appraisal Tool (MMAT) (Pluye and Hong 2014) was used to evaluate research studies included in the review. MMAT is a comprehensive appraisal tool developed for reviews involving qualitative, quantitative and mixed methods studies. The criteria refers to four domains which are specific to each type of study. For non-research documents including clinical case reports, expert opinions and service description, the AACODS grey literature checklist was used (Tyndall 2010). This checklist consists of six criteria comprising specific questions to guide evaluation. The rationale for using this checklist is that all these non-research documents fall into the category of "expert opinion" and can be treated as grey literature (Tyndall 2010).

The papers were critically appraised by $\mathrm{YL}$ under supervision of $\mathrm{NJ}$ and $\mathrm{MM}$. Although the quality of many papers was poor and some papers had missing information, taking into account the small number of papers that met the inclusion criteria, no paper was excluded on grounds of quality.

\section{Data extraction}

Data on background information and patient details were extracted to a standardised form, including country, type of source, transfer size, unit, sex, age, diagnosis, decision-making capacity, life-sustaining treatment and time to death. Transfer home decision-making, the work involved, and information that promoted or inhibited implementation were extracted into a separate form. For papers that did not provide specific patient cases, data extraction included country, perspective of investigation, participants, study design/methods and main findings about transfer decision-making.

\section{Data synthesis}

An adapted framework synthesis approach was used to analyse the extracted data (Ritchie and Spencer 2002). This process comprised two stages: inductive comparative analysis and subsequent deductive framework mapping (Figure 2). In the first stage, data about transfer home and its decision-making were coded and categorised to enable the identification of themes through data display and comparison (Miles and Huberman 1994). In the second stage, in order to explain the emergent themes, a theoretical framework was used for data 
interpretation which was informed by Normalization Process Theory (NPT) (May and Finch 2009). To avoid making the data fit the framework and to identify if emerging themes fell outside of it, an 'other' category was applied.

NPT is an action theory, focusing on how complex practice is implemented, embedded and integrated in routine practice. It proposes four main constructs: coherence, cognitive participation, collective action and reflexive monitoring. These are associated with the investments people make in sense-making, commitment, enacting, and appraising the implementation of complex practice. The key questions appear in the four constructs and are 1) what is the work?; 2) who does the work?; 3) how does the work get done?; and 4) how is the work understood? (May and Finch 2009).

The focus of the four kinds of work distinguishes NPT from other sociological theories such as the Theory of Planned Behaviour, which concerns the relationship between individual attitudes and intentions and behavioural outcomes (Ajzen 1991). The core of NPT is how to "normalise" a complex intervention in daily work as distinct from "institutionalisation" which is the focus of the theory Diffusion of Innovations (Rogers Everett 1995) and Actor-Network Theory (Latour 2005), as normalisation comprises the final destination: stabilisation (May and Finch 2009).

Transferring critically ill patients home to die is recognized to be complex by healthcare professionals (HCPs) (Coombs et al. 2014), and NPT can enable the identification and understanding of the complexity of such practice and its decision-making implementation, by investigating the four constructs (May 2013). NPT has been shown to be a robust conceptual model that drives qualitative analysis (MacFarlane and O'Reilly-De Brún 2012), especially in implementation studies (Myall et al. 2015), including systematic reviews (Gallacher et al. 2013; McEvoy et al. 2014; Lund et al. 2015). Therefore, NPT was chosen to explain the themes emerging from data.

In the second stage, working questions for transfer home were developed initially on the basis of the review questions and the four NPT constructs. These guided the mapping of the emergent categories from initial analysis onto the four constructs. Finally, themes of transfer decision-making work were generated.

\section{Results}

Among the 20 articles, 15 documented the practice of transfer home in seven different health care systems and social contexts (Table 2). The number of patients transferred home ranged from one to 346 , with most reporting on the transfer of one or two patients. Some information about the characteristics of patients in five of the 15 articles were missing. The 
remaining five papers (Table 3) did not describe specific patient cases but investigated the transfer home practice generally in the UK, and predominately from the perspective of HCPs.

Originally, seven themes and 21 sub-themes were identified inductively through coding (See supplementary information 3). After mapping these emergent themes to the NPT constructs, four themes concerning the complex work of transfer decision-making were generated (See supplementary information 4) and could be mapped onto the NPT framework.

\section{Theme 1: Divergent views and practice on patients' conditions}

Generally, individuals involved agreed that transferring dying patients home was necessary if home was the preferred place of death for patients. However, in defining who could be transferred home, there was no consensus on the patient's conditions across units or countries in terms of consciousness, stability, intubation and ventilation. In the west, only stable patients without intubation and ventilation would be transferred home to die. While for Maori, Polynesian, Tunisian and Taiwanese, mainly located in 'the east', unstable patients with intubation and ventilation could be transferred home.

Generally HCPs in the UK believed that dying patients who have decision-making capacity, and request to go home, should be considered for transfer home (Coombs et al. 2014). HCPs' views were based on the belief that the quality of home death would be better than a CCU death and respect for the patient could be achieved by fulfilling their wish. Indeed, some patients who were unconscious were also transferred in the USA and Tunisia (Kallel et al. 2006; Crighton et al. 2008). This request was made by families on behalf of patients who were aware that this was their relative's preference. In these cases families believed that taking home their dying relatives was in the best interest of the patient.

In many western countries, unstable and ventilated patients were unable to be transferred home. In a UK survey, more than half of HCPs said they would not consider transferring unstable $(61.8 \%)$, or intubated and ventilated patients (68.5\%) (Darlington et al. 2013). Similarly, in the USA stable patients were transferred and could survive for months after transfer (Creechan 2000; Crighton et al. 2008). Lusardi et al. (2011) reported in their practice only stable patients without life-sustaining treatment were transferred. This was based on a belief that the patient might not survive transfer or that the healthcare staff could not cope with the implementation of transfer. Also in the Netherlands, stable patients were extubated in ICU before transfer as home mechanical ventilation was considered unfeasible (Beuks et al. 2006).

However, in New Zealand (Mann et al. 2004; Ryder-Lewis 2005), Tunisia (Boussarsar and Bouchoucha 2006; Kallel et al. 2006) and Taiwan (Huang et al. 2009) where home death was a cultural or religious requirement, patients who were unstable, facing imminent death, 
or ventilated were transferred home. In these circumstances, the purpose of transfer was not to improve quality at the end of life but meet cultural needs. New Zealand Maori or Polynesian, Tunisian, and Taiwanese tended to prefer to die at home surrounded by family, sometimes with a ritual regarding home death. Patients whose cultural or religious beliefs necessitated home death tended to be more medically unstable. For example, Huang et al. (2009) suggested that only when a patient's systolic blood pressure was $<80 \mathrm{mmHg}$ and death was imminent, discharge home commenced because home death was a cultural tradition in Chinese society.

The decision-making to transfer dying patients home was complex with divergent views on patients' conditions, different healthcare systems, and cultural or religious requirements for home death impacting on the decision-making.

\section{Theme 2: Multiple stakeholders involved decision-making}

Multiple stakeholders were involved in the transfer decision-making including patients, families, CCU staff, palliative care, hospice, and community care teams.

Families played a vital role in decision-making processes. Ryder-Lewis (2005) argued a key point to the transfer was a family's desire to take their dying relative home. In addition, the relationship between family and HCPs was highlighted regarding transfer decision-making. Mann et al. (2004) stated the selection of patients to transfer was based on the trust relationship between staff and family. Ryder-Lewis (2005) also considered families as partners in the course of transfer home.

Transfer decision-making processes also involved multi-disciplinary HCPs. In many cases, hospice (Poucher 2010; Lusardi et al. 2011) or palliative care clinicians (Crighton et al. 2008; Kumar et al. 2009; Tellett and Davis 2009; Clinch and Le 2011; Campbell 2013) were involved in the transfer discussion or arrangement. Other people involved included hospital administrators, transport personnel, coroners, bereavement teams and social workers (Creechan 2000; Mann et al. 2004; Ryder-Lewis 2005; Kumar et al. 2009; Clinch and Le 2011; Battle et al. 2014).

The cooperation from community care teams was identified by HCPs as central to ensuring the transfer (Ryder-Lewis 2005; Coombs et al. 2014). Communication with GPs, district nurses, local hospice or palliative HCPs was needed to ensure they were willing to engage and understand what was required around transfer (Ryder-Lewis 2005). However, community staff might not have the competence to be involved in a level of care if this required undertaking tasks beyond their routine work (Clinch and Le 2011; Battle et al. 2014). 
In summary, individuals involved in transfer decision-making came from different disciplines or organizations. This could make it challenging to coordinate communication among stakeholders and contributed to the complexity of transfer decision-making.

\section{Theme 3: Collective action involving transition and integration of care}

The operationalization of transfer home brought HCPs together from critical care, palliative or hospice, and community care in respect of implementation of transfer, withdrawal of treatment and home care (Ryder-Lewis 2005; Coombs et al. 2014). Transition from intensive care to home care and integration of HCPs' formal care and families' informal care coexisted in this medical event.

In practice, transfer home was largely carried out by critical care nurses (Mann et al. 2004; Ryder-Lewis 2005; Boussarsar and Bouchoucha 2006; Huang et al. 2009; Kumar et al. 2009; Tellett and Davis 2009; Battle et al. 2014; Coombs et al. 2014). In one case the initial transfer home was accompanied by a doctor (Battle et al. 2014). In the UK, palliative care teams were reported to undertake the transfer of dying patients (Murphy et al. 2004). Following the establishment of guidance for transfer and once training was undertaken; responsibility for carrying out the transfer process was mostly allocated to CCU nurses.

Once the decision to transfer home has been made, subsequent decisions were required regarding where withdrawal of treatment took place - in the CCU or at home. Some patients' treatments were withdrawn in CCU before transfer (Tellett and Davis 2009; Lusardi et al. 2011). Conversely, a number of patients went home with life-sustaining treatments including ventilation and/or cardiovascular medications, and withdrawal was carried out at home (Creechan 2000; Mann et al. 2004; Ryder-Lewis 2005; Boussarsar and Bouchoucha 2006; Kallel et al. 2006; Huang et al. 2009; Kumar et al. 2009; Clinch and Le 2011; Battle et al. 2014). Intensive treatments, such as intubation and ventilation were more likely to be withdrawn in CCUs to avoid the risk associated with carrying out the procedure in the patient's home where CCU staff were no longer familiar with the environment and resources were limited (Clinch and Le 2011).

Following transfer, home care was mainly provided by families with support from community care services. Caring for a dying patient at home could be challenging and family members had to be able to cope physically and emotionally (Ryder-Lewis 2005; Coombs et al. 2014); inability to cope with witnessing a loved one dying at home could lead to their refusal of transfer (Lusardi et al. 2011).

In most cases community HCPs, including GPs, district nurses and local hospice or palliative care professionals, offered care in the patients' home after transfer (Mann et al. 2004; Ryder-Lewis 2005; Kumar et al. 2009; Tellett and Davis 2009; Clinch and Le 2011; Lusardi 
et al. 2011; Battle et al. 2014; Coombs et al. 2014). A lack of community resources for some patients was an obstacle identified in one paper (Lusardi et al. 2011). Dying patients would not be transferred home until the HCPs who would care for them were in place (Lusardi et al. 2011).

In summary, different types of work to achieve home death were required as the collective action by HCPs from CCUs, hospice or palliative and community, as well as family members. Transfer decision-making was complex when the work involved the transition from curative care to end-of-life care, intensive care to home care, and the integration of informal and formal care.

\section{Theme 4: Appraising the decision of transfer home}

On the whole, positive appraisal was made by patients, families and HCPs. With the exception of the in-depth investigation of this practice from HCPs' perspective in the UK, information about individuals' understanding of this practice and decision-making was limited as their evaluations were sought informally and briefly.

Most families expressed gratitude for the patient's home death to CCU clinicians (Mann et al. 2004; Ryder-Lewis 2005; Beuks et al. 2006; Boussarsar and Bouchoucha 2006; Kallel et al. 2006; Kumar et al. 2009; Lusardi et al. 2011; Battle et al. 2014). More importantly, some families and HCPs believed the patient's home death constituted a good death (Ryder-Lewis 2005; Beuks et al. 2006; Kumar et al. 2009; Poucher 2010; Battle et al. 2014).

In terms of decision-making, some suggestions for improving the transfer process were made by families. They felt it was important to involve them in the decision-making (Tellett et al. 2012) and, although difficult to predict, providing accurate and timely information on prognosis was considered essential (Crighton et al. 2008; Tellett et al. 2012; Campbell 2013). One patient suggested that the burden placed on the family was an important consideration in the decision-making (Creechan 2000). Decision-making appeared an important aspect in the families' feedback on transfer.

Experiences of HCPs from palliative, hospice and community have not been widely reported. In one case, a hospice team was fearful about caring for a patient with a tracheotomy and ventilation at home, and training was provided to increase their confidence to carry out the care needed (Creechan 2000). The impact on HCPs of transferring dying patients home was mentioned briefly in the study by Mann et al. (2004) which reported that some nurses felt "uncomfortable" with undertaking the transfer. However, this was not explored further in their paper. 
According to NPT, individuals' appraisal serves as a factor that promotes or inhibits the implementation of complex practice. Hence, the limited information on appraisal, particularly from families and community HCPs became a factor preventing the implementation of transferring home dying patients from CCUs.

\section{Discussion}

Overall, a limited number of patients were transferred home to die from CCUs. It was relatively rare in many western countries but more common in those in the east where home death was a cultural or religious need.

In spite of missing information in some articles a better understanding was obtained about how decisions were made to transfer patients home to die from CCUs. It encompassed decisions about: criteria for patients to be transferred, stakeholders involved in the decisionmaking process and the nature of their involvement; the collective work for transfer; and stakeholders' reflection on these decisions. Through the lens of NPT (May 2013), barriers for the transfer decision-making were identified in terms of the four types work with a lack of reflection and evaluation from stakeholders revealed as a major challenge.

Findings from this review suggest where the transfer decision-making could be improved and normalised within routine critical care. Transfer decision-making should be culturally sensitive, as culture, ethnicity and religious beliefs can impact on end-of-life decision-making (Bülow et al. 2008; Fang et al. 2016). For groups of Maori, Polynesian, Tunisian and Taiwanese, to die at home was a requirement of ethnicity, culture or religion (Ryder-Lewis 2005; Boussarsar and Bouchoucha 2006; Huang et al. 2009). Kompanje (2009) argued that it does not make sense to transfer home unconscious patients to die because of their inability to experience that death, but agreed that this could be meaningful for patients when dying at home was a cultural or religious need.

Little understanding was obtained about how various groups were involved in the transfer decision-making, such as the role each played and the dynamics involved. This review affirmed the importance of the well-described themes of shared decision-making (SDM) in the literature (Charles et al. 1997, 1999a; Makoul and Clayman 2006; White et al. 2007; Legare et al. 2008). SDM emphasizes sharing information, involvement, trust and partnership among patients, their families and HCPs (Charles et al. 1997, 1999a; Charles et al. 1999b). May (2013) viewed SDM as a complex innovation in healthcare through the lens of NPT. Our review identified that the complex transfer decision-making could be an exemplar of SDM as the transfer decision-making involved patients, families and multi-team of HCPs to achieve same goals of care. However, taking into account the unpreparedness of 
CCU nurses and community HCPs involved, combined with a lack of evidence of decisionmaking dynamics, the transfer decision-making appeared not conform to usual SDM practice. Based on findings from this review the consensus view of considering both integration and transition of care in CCUs and patients' home when making the decision of transfer home is advocated. There is a common recognition of the necessity to integrate palliative care in CCUs (Clarke et al. 2003; Campbell 2006; Anderson-Shaw 2010; Nelson et al. 2010). This also shows that transfer home is more complex as not only palliative care but also hospice, community care, and home care are involved in this practice. Also, the transition from critical care to home care, with the purpose of dying at home, increases complexity of the transfer decision-making. A number of studies have investigated home care for dying patients provided by families and home care services (Gomes and Higginson 2006; O'Brien and Jack 2010; Gomes et al. 2013a). However, hospice decision-making is seen as an evolving process (Romo et al. 2016). The integration and transition of care from CCUs to patients' home revealed in this review suggested the situation should be viewed as a continuous and dynamic process.

A major omission identified in the literature was the lack of formal evaluations from individuals involved. To understand and eventually normalise the transfer decision-making, it is essential to know the views and experiences of key stakeholders. Nurses played a unique role as the transfer process was led predominately by them, but no information was found regarding their role in the decision-making. Nurses' feedback, which would be valuable for understanding and improving this complex practice, therefore remains unclear.

Compared to other countries included in this review, more investigations of transfer practice have been undertaken in the UK. For example, through a three-phase project exploring HCPs' experiences and views, and using consensus methods, Coombs et al. (2015b) developed guidance for clinical practice. Their findings allowed an in-depth understanding of the situation in the UK from the perspective of HCPs, which has been summarized in this review.

\section{Strength and limitations}

To our knowledge, this is the first integrative review to uncover the complex decision-making of transferring home dying patients from CCUs placed in an international context. The review has considered broad and heterogeneous information which contributed to the in-depth understanding of the current state of knowledge on the decision-making of transfer home. First, an international investigation of transfer practice and synthesis of evidence was achieved. Second, papers that investigated this phenomenon with different designs, methods or perspectives were included. Third, this review avoided a narrow focus on the 
literature of transfer home only in ICUs, but also included other critical care settings (NICE 2009; NHS Choices 2015).

The complexity of transfer decision-making has been explained through the theoretical lens of NPT. There was strong resonance between the emergent themes and the NPT constructs. In addition, as had been concluded by other studies (Gallacher et al. 2013; McEvoy et al. 2014; Lund et al. 2015), this review shows NPT is an appropriate theoretical framework to facilitate analysis of heterogeneous data from sources concerning complex clinical practice.

The main limitation of this review is in the selection bias of included papers. We did not find any relevant papers written in Chinese resulting in only those written in English being included. This contributes to cultural bias as review findings were largely generated from evidence sources in western countries.

A further limitation is the quality of papers included. While we undertook a quality appraisal to inform our interpretations we did not exclude papers solely on the grounds of low quality; this may have impacted on the overall quality of the findings.

\section{Implications for practice and research}

This review provided HCPs with further insights into the complexity of transfer decisionmaking. Nurses can actively engage in the decision-making process through sharing information and working in partnership with the multi-disciplinary team. More importantly as nurses predominately lead and carry out the transfer, their views should be highly valued.

Transferring dying patients home remains an under-researched area and more in-depth research is needed. The findings of this review were mainly derived from the perspective of hospital-based HCPs. Further research is needed to investigate this medical practice from the perspective of CCU nurses, families, palliative or hospice and community care professionals. Additionally, the variation in practice across countries suggests the need for further research to investigate the contexts of countries outside the west where transfer is achieved more often, for example, in Asia. Such evidence could inform the development of guidelines for transfer decision-making and identify the work required to routinely incorporate and embed the transfer into practice when appropriate. Also, training programmes for HCPs, including critical care nurses, to support the implementation of transferring a patient home to die could facilitate the embedding and incorporation of this process and its eventual normalization.

\section{Conclusion}

Overall, transferring home dying patients from CCUs is a complex medical event that happens in many different healthcare systems and social contexts. The practice and its 
prevalence varies substantially between countries in the east and west. A better understanding of the complex work for transfer decision-making has been obtained from this review, however the limited available literature means that all the work needed, all the decisions required and the perspectives of all involved stakeholders have yet to be fully revealed. Further research is needed to address these gaps to inform the development of guidance for transfer so that the wishes of more patients to die at home can be met. 


\section{References}

Ajzen I (1991) The theory of planned behavior. Organizational behavior and human decision processes 50(2): 179-211

Anderson-Shaw L (2010) Consultative or integrative, palliative care must be part of intensive care unit care. Critical Care Medicine 38(9): 1904-1904

Angus DC, Barnato AE, Linde-Zwirble WT, Weissfeld LA, Watson RS, Rickert T and Rubenfeld GD (2004) Use of intensive care at the end of life in the United States: An epidemiologic study*. Critical Care Medicine 32(3): 638-643

Battle E, Bates L, Liderth E, Jones S, Sheen S, Ginty A and Northmore M (2014) Enabling ICU patients to die at home. Nursing Standard 29(5): 46-49

Bauchmuller K and Faulds MC (2015) Critical illness and intensive care: I: Care of the critically ill patient. Surgery (Oxford) 33: 165-171

Beuks BC, Nijhof AC, Meertens JHJM, Ligtenberg JJM, Tulleken JE and Zijlstra JG (2006) A good death. Intensive care medicine 32(5): 752-753

Blot S, Afonso E and Labeau S (2015) Recent advances in multidisciplinary critical care. American Journal of Critical Care 24(1): 75-86

Boussarsar M and Bouchoucha S (2006) Dying at home: Cultural and religious preferences. Intensive care medicine 32(11): 1917-1918

Broad JB, Gott M, Kim H, Boyd M, Chen H and Connolly MJ (2013) Where do people die? An international comparison of the percentage of deaths occurring in hospital and residential aged care settings in 45 populations, using published and available statistics. International Journal of Public Health 58(2): 257-267

Bülow HH, Sprung CL, Reinhart K, Prayag S, Du B, Armaganidis A, Abroug F and Levy MM (2008) The world's major religions' points of view on end-of-life decisions in the intensive care unit. Intensive care medicine 34(3): 423-430

Campbell L (2013) Opinion piece: Honouring the wishes of a dying patient: From intensive care to home with palliative care. Contemporary Nurse 45(2): 269-272

Campbell ML (2006) Palliative care consultation in the intensive care unit. Critical Care Medicine 34(11): S355-8

Charles C, Gafni A and Whelan T (1997) Shared decision making in the medical encounter: what does it mean?(or it takes at least two to tango). Social Science \& Medicine 44(5): 681-692

Charles C, Gafni A and Whelan T (1999a) Decision making in the physician-patient encounter: revisiting the shared treatment decision-making model. Social Science \& Medicine (49): 651661

Charles C, Whelan T and Gafni A (1999b) What do we mean by partnership in making decisions about treatment? British Medical Journal 319(18): 780-782.

Clarke EB, Curtis JR, Luce JM, Levy M, Danis M, Nelson J and Solomon MZ (2003) Quality indicators for end-of-life care in the intensive care unit. Critical Care Medicine 31(9): 2255-2262

Clinch A and Le B (2011) Withdrawal of mechanical ventilation in the home: A case report and review of the literature. Palliative medicine 25(4): 378-381

Cohen J, Pivodic L, Miccinesi G, Onwuteaka-Philipsen BD, Naylor WA, Wilson DM, Loucka M, Csikos A, Pardon K, Van Den Block L, Ruiz-Ramos M, Cardenas-Turanzas M, Rhee Y, Aubry R, Hunt K, 
Teno J, Houttekier D and Deliens L (2015) International study of the place of death of people with cancer: a population-level comparison of 14 countries across 4 continents using death certificate data. British Journal of Cancer 113(9): 1397-1404

Conn VS, Isaramalai SA, Rath S, Jantarakupt P, Wadhawan R and Dash Y (2003a) Beyond MEDLINE for literature searches. Journal of Nursing Scholarship 35(2): 177-182

Conn VS, Valentine JC, Cooper HM and Rantz MJ (2003b) Grey literature in meta-analyses. Nursing Research 52(4): 256-261

Coombs M, Long-Sutehall T, Darlington AS and Richardson A (2014) Doctors' and nurses' views and experience of transferring patients from critical care home to die: A qualitative exploratory study. Palliative medicine: 1-9

Coombs MA, Darlington AE, Long-Sutehall T, Pattison N and Richardson A (2015a) Transferring patients home to die: what is the potential population in UK critical care units? BMJ Supportive \& Palliative Care: bmjspcare-2014-000834

Coombs MA, Darlington AS, Long-Sutehall T and Richardson A (2015b) Transferring critically ill patients home to die: developing a clinical guidance document. Nursing in critical care: 1-7

Creechan T (2000) Combining mechanical ventilation with hospice care in the home: death with dignity. Critical Care Nurse 20(3): 49-53

Crighton MH, Coyne BM, Tate J, Swigart V and Happ MB (2008) Transitioning to end-of-life care in the intensive care unit: a case of unifying divergent desires. Cancer Nursing 31(6): 478-484

Darlington ASE, Long-Sutehall T, Addington-Hall J, Richardson A and Coombs MA (2013) A National Survey Exploring Views and Experience of Health Professionals About Transferring Patients from Critical Care Home to Die. BMJ Supportive \& Palliative Care 3(1): 125-125

Fang ML, Sixsmith J, Sinclair S and Horst G (2016) A knowledge synthesis of culturally- and spirituallysensitive end-of-life care: findings from a scoping review. BMC Geriatrics 16(1): 107

Gallacher K, Morrison D, Jani B, Macdonald S, May CR, Montori VM, Erwin PJ, Batty GD, Eton DT, Langhorne P and Mair FS (2013) Uncovering treatment burden as a key concept for stroke care: a systematic review of qualitative research. PLoS Medicine 10(6): e1001473

Gomes B, Calanzani N, Curiale V, McCrone P and Higginson IJ (2013a) Effectiveness and costeffectiveness of home palliative care services for adults with advanced illness and their caregivers. The Cochrane database of systematic reviews 6: CD007760

Gomes B, Calanzani N, Gysels M, Hall S and Higginson IJ (2013b) Heterogeneity and changes in preferences for dying at home: A systematic review. BMC Palliative Care 12: 7

Gomes B, Calanzani N, Koffman J and Higginson I (2015) Is dying in hospital better than home in incurable cancer and what factors influence this? A population-based study. BMC Medicine 13(1): 235

Gomes B and Higginson IJ (2006) Factors influencing death at home in terminally ill patients with cancer: Systematic review. British Medical Journal 332(7540): 515-518

Hoogveld LMT, Bergmans DCJJ, de Vries S, van Proemeren $\mathrm{H}$, van den Beuken-van Everdingen $\mathrm{MHJ}$, Zijlstra JG and van Mook WNKA (2015) Intensive care patients who want to die at home: how can we fulfil this last wish? Nederlands Tijdschrift Voor Geneeskunde 159: A8711-A8711

Huang YC, Huang SJ and Ko WJ (2009) Going home to die from surgical intensive care units. Intensive care medicine 35(5): 810-815

Kallel H, Dammak H, Bahloul M, Hamida CB, Chelly H, Rekik N and Bouaziz M (2006) A good death: another break in the wall. Intensive care medicine 32(11): 1915-1916 
Kompanje EJO (2009) Should we discharge comatose patients from intensive care to die in their own bed at home after withdrawal of mechanical ventilation? Intensive care medicine 35(5): 773774

Kumar G, Obuch S and Vyakarnam P (2009) Withdrawal of intensive care treatment at home - 'A good death'. Anaesthesia and intensive care 37(3): 484-486

Latour B (2005) Reassembling the social-an introduction to actor-network-theory. Oxford: Oxford University Press

Legare F, Ratte S, Gravel K and Graham ID (2008) Barriers and facilitators to implementing shared decision-making in clinical practice: Update of a systematic review of health professionals' perceptions. Patient Education and Counseling 73(3): 526-535

Lilly CM, Zuckerman IH, Badawi O and Riker RR (2011) Benchmark data from more than 240,000 adults that reflect the current practice of critical care in the United States. Chest 140(5): 1232-1242

Lund S, Richardson A and May C (2015) Barriers to advance care planning at the end of life: an explanatory systematic review of implementation studies. PLoS One 10(2): e0116629

Lusardi P, Jodka P, Stambovsky M, Stadnicki B, Babb B, Plouffe D, Doubleday N, Pizlak Z, Walles K and Montonye $M$ (2011) The going home initiative: getting critical care patients home with hospice. Critical Care Nurse 31(5): 46-57

MacFarlane A and O'Reilly-De Brún M (2012) Using a theory-driven conceptual framework in qualitative health research. Qualitative Health Research 22(5): 607-618

Makoul G and Clayman ML (2006) An integrative model of shared decision making in medical encounters. Patient Education and Counseling 60(3): 301-312

Mann S, Galler D, Williams P and Frost P (2004) Caring for patients and families at the end of life: Withdrawal of intensive care in the patient's home. New Zealand Medical Journal 117(1196): $1-8$

May C (2013) Agency and implementation: understanding the embedding of healthcare innovations in practice. Social Science \& Medicine 78: 26-33

May C and Finch T (2009) Implementing, Embedding, and Integrating Practices: An Outline of Normalization Process Theory. Sociology 43(3): 535-554

May CR, Mair F, Finch T, MacFarlane A, Dowrick C, Treweek S, Rapley T, Ballini L, Ong BN, Rogers A, Murray E, Elwyn G, Légaré F, Gunn J and Montori VM (2009) Development of a theory of implementation and integration: Normalization Process Theory. Implementation Science 4: 29

McEvoy R, Ballini L and Maltoni S (2014) A qualitative systematic review of studies using the normalization process theory to research implementation processes. Implementation Science 9: 2-14

Miles MB and Huberman AM (1994) Qualitative data analysis: An expanded sourcebook (2nd Edition). Thousand Oaks: SAGE

Murphy D, Ellershaw JE, Jack B, Gambles M and Saltmarsh P (2004) The Liverpool Care Pathway for the rapid discharge home of the dying patient. Journal of Integrated Care Pathways 8(3): 127-128

Murray E, Treweek S, Pope C, MacFarlane A, Ballini L, Dowrick C, Finch T, Kennedy A, Mair F, O'Donnell C, Ong BN, Rapley T, Rogers A and May C (2010) Normalisation process theory: A 
framework for developing, evaluating and implementing complex interventions. $B M C$ Medicine 8: 63

Myall M, May CR, Grimmett C, May CM, Calman L, Richardson A and Foster CL (2015) RESTORE: an exploratory trial of a web-based intervention to enhance self-management of cancer-related fatigue: findings from a qualitative process evaluation. BMC Medical Informatics and Decision Making 15(1): 94

Nelson JE, Bassett R, Boss RD, Brasel KJ, Campbell ML, Cortez TB, Curtis JR, Lustbader DR, Mulkerin C, Puntillo KA, Ray DE and Weissman DE (2010) Models for structuring a clinical initiative to enhance palliative care in the intensive care unit: a report from the IPAL-ICU Project (Improving Palliative Care in the ICU). Critical Care Medicine 38(9): 1765-1772

NHS Choices (2015) Intensive care. Available from: http://www.nhs.uk/conditions/Intensivecare/Pages/Introduction.aspx [Accessed 23 September 2015]

NICE (2009) Information for the public: Rehabilitation after critical illness. Available from: https://www.nice.org.uk/guidance/cg83/ifp/chapter/what-critical-care-means [Accessed 12 September 2015]

O'Brien M and Jack B (2010) Barriers to dying at home: The impact of poor co-ordination of community service provision for patients with cancer. Health and Social Care in the Community 18(4): 337-345

Pluye $P$ and Hong QN (2014) Combining the power of stories and the power of numbers: mixed methods research and mixed studies reviews. Annual Review of Public Health 35: 29-45

Poucher HK (2010) The Going Home Initiative: facilitating a 'good death' at home for critically ill patients. Advance for Nurses: 22-24

Ritchie J and Spencer L (2002) Qualitative data analysis for applied policy research IN: Huberman M and Miles MB (eds) The qualitative researcher's companion. California: Sage 305-329

Rogers Everett M (1995) Diffusion of innovations (4th Edition). New York: Free Press

Romo RD, Wallhagen MI and Smith AK (2016) Viewing Hospice Decision Making as a Process. American Journal of Hospice and Palliative Medicine 33(5): 503-510

Ryder-Lewis M (2005) Going home from ICU to die: a celebration of life. Nursing in critical care 10(3): $116-122$

Soares CB, Hoga LAK, Peduzzi M, Sangaleti C, Yonekura T and Silva DRAD (2014) Integrative review: concepts and methods used in nursing. Revista da Escola de Enfermagem da USP 48(2): 335345

Tellett $L$ and Davis C (2009) The case study masterclass. Case 43. Fulfilling a patient's wish to go home from intensive care. European Journal of Palliative Care 16(2): 69-70

Tellett L, Pyle L and Coombs M (2012) End of life in intensive care: Is transfer home an alternative? Intensive and Critical Care Nursing 28(4): 234-241

Ten Ham W, Minnie K and Van der Walt C (2016) Integrative review of benefit levers' characteristics for system-wide spread of best healthcare practices. Journal of Advanced Nursing 72(1): 3349

Tyndall J (2010) AACODS checklist. Flinders University. Available from: https://dspace.flinders.edu.au/jspui/bitstream/2328/3326/4/AACODS Checklist.pdf [Accessed 5 October 2016]

White DB, Braddock CH and Bereknyei S (2007) Toward shared decision making at the end of life in intensive care units. Archives of Internal Medicine 167: 461-467 
Whittemore R and Knafl K (2005) The integrative review: updated methodology. Journal of Advanced Nursing 52(5): 546-553

Wunsch H, Harrison DA, Harvey S and Rowan K (2005) End-of-life decisions: a cohort study of the withdrawal of all active treatment in intensive care units in the United Kingdom. Intensive care medicine 31(6): 823-831

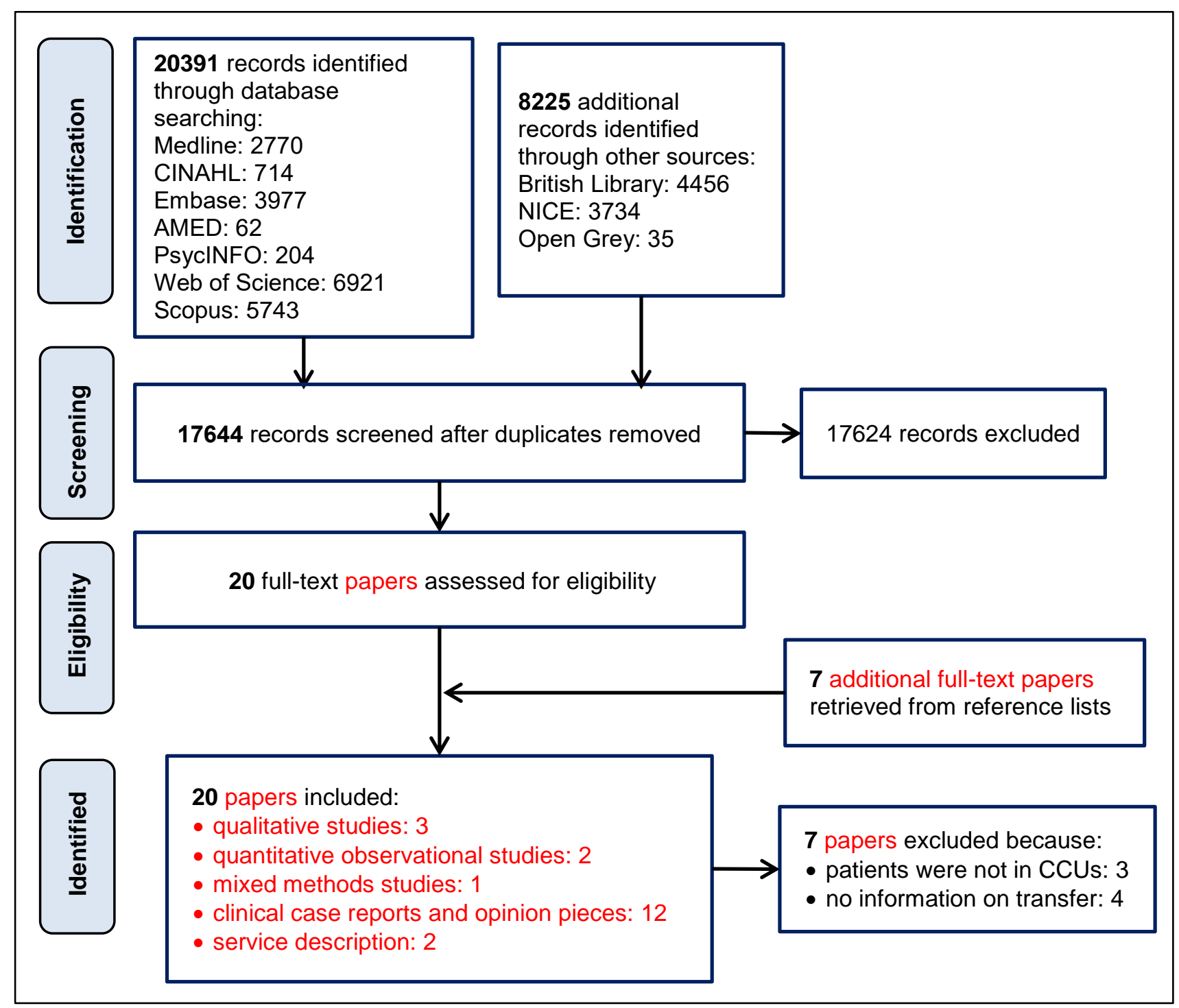

Figure 1 Paper selection results 
